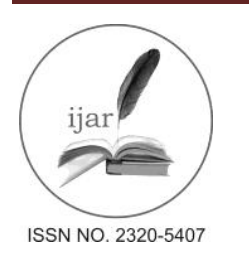

\author{
Journal homepage: http://www.journalijar.com

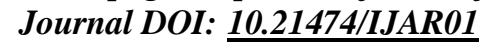

INTERNATIONAL JOURNAL

OF ADVANCED RESEARCH

RESEARCH ARTICLE

\title{
DEVELOPMENT AND EVALUATION OF PREGABALIN TRANSDERMAL PATCH FOR THE TREATMENT OF NEUROPATHETIC PAIN.
}

\author{
*Akshata M. Kulkarni, Dr. Pravin D. Chaudhari and Dr. Pravin S. Uttekar. \\ Progressive Education Society's Modern College of Pharmacy, Sector no. 21, Yamunanagar, Nigdi, Pune-44, \\ Maharashtra, India.
}

\section{Manuscript Info}

Manuscript History:

Received: 18 May 2016

Final Accepted: 22 June 2016

Published Online: July 2016

Key words:

Pregabalin; Transdermal; HPMC E-

15; Eudragit RS-100.

*Corresponding Author

Akshata M. Kulkarni.

\begin{abstract}
Transdermal drug delivery systems are becoming more popular in the field of modern pharmaceutics. The objective of this study is to determine the permeation of Pregabalin from transdermal patch into microcirculation of skin. Matrix type transdermal drug delivery system (TDDS) of Pregabalin was prepared by the solvent evaporation technique. Several batches were prepared by using combination of HPMC E-15 and Eudragit RS-100 different ratios. Propylene glycol was used as plasticizer and DMSO was incorporated as a permeation enhancer. Formulated transdermal patches were characterized for their physicochemical parameters like thickness, weight variation, folding endurance, percentage moisture uptake and drug content uniformity.The in-vitro permeation studies were performed using Franz diffusion cell. Patches were evaluated for their ex-vivo skin permeation studies. The possible drug polymer interactions were studied by FTIR.Formulation F-9 containing HPMC E-15 and Eudragit RS100 in the ratio of 200:600mg, propylene glycol 30w/v and DMSO 30\%w/v was found to be the most optimum formulation and also found to exhibit maximum invitro \%drug release for about $11.2 \mathrm{hrs}$. Result of evaluation studies showed that Pregabalin can be administered as a controlled drug delivery system to reduce frequency of drug administration.
\end{abstract}

Copy Right, IJAR, 2016,. All rights reserved.

\section{Introduction:-}

Pregabalin (PGB) is an anticonvulsant and analgesic drug [1].Pregabalin (S) - 3 - amino methyl hexanoic acid, is a structural analogue of $\gamma$-amino butyric acid (GABA). They constitute an important group of compounds that are used in the treatment of epilepsy and neuropathic pain [2], which is required to be administered three to four times per day for its therapeutic effect by oral route of drug delivery in the treatment of partial seizures. It also finds its use in peripheral diabetic neuropathy, fibromyalgia and post-therapeutic neuralgia. So, the objective of present work is to develop a controlled release dosage form of Pregabalin other than oral route and injectables. Hence, a noninvasive system in the form of transdermal patch of Pregabalin was thought to be developed and evaluated with the aim of achieving controlled release of Pregabalin over a prolong time period so that frequency of drug administration will be minimized[3-4].

Transdermal drug delivery has certain advantages over other systems of drug administration which in turn leads to increase patient compliance. Its non-invasive nature, ease of application and removal, predetermined rate of drug permeation, increased bioavailability of drug and decreased hepatic metabolism; all these factors make this system most suitable for systemic delivery of drug over long time periods of $24 \mathrm{hrs}$. The half-life of Pregabalin is also short (5- $6.5 \mathrm{hrs)}$ which makes it suitable candidate for sustained release formulation, moreover in reducing side effects, decreasing frequency and improve patient compliance.[5-8] 
Pregabalin binds with high affinity to the alpha2-delta site (an auxiliary subunit of voltage gated calcium channels) in central nervous system tissues. Pregabalin reduces the calcium-dependent release of several neurotransmitters, possibly by modulation of calcium channel function. Pregabalin is well absorbed after oral administration. When an oral administration of pregabalin under fasting conditions is given, the pharmacokinetic parameters are as follows: tmax was 1.5 hours and the oral bioavailability of $>90 \%$ (independent of dose); time to steady state concentration is 24-48 hours.

\section{Materials and Method:- \\ Materials:-}

Pregabalin was obtained as gift sample from Emcure Pharmaceuticals, Pune. Polymers such as HPMC E-15, PVA, Eudragit RS-100 and other chemicals such as propylene glycol and DMSO and methanol provided by the institute (Modern College of Pharmacy,Nigdi) used in the study were of analytical grade.

\section{Method:-}

Matrix type Transdermal patch of Pregabalin was prepared by solvent evaporation technology. In this technology, mixture of polymer and drug solution as given in Table 1, was spread as a film on a suitable support (glass, mercury, aluminum foil, etc.) $4 \%$ PVA solution initially dried on petri plate was used as backing membrane and fixed volume of $(10 \mathrm{~mL})$ of polymeric solution with drug, plasticizer and penetration enhancer was poured on the petri dish for 24hours generally at room temperature, as shown in Fig 1 and Fig 2 . The dried films were removed and cut into 2 $\mathrm{cm}^{2}$ area and kept in desiccators until used. The patch thus obtained was then evaluated for various parameters like physicochemical parameters, drug content, and drug release profile and for skin irritation studies. [9-10]

\section{Evaluation of Drug Loaded Patches of HPMC E-15 and Eudragit RS-100:- Physicochemical Evaluation:-}

Physical Appearance:- Formulated patches were evaluated for their physical appearance, uniformity, entrapment of any air bubble or precipitation of drug, which on a large part determines patient acceptability of the patch and also therapeutic efficacy.[11]

Thickness:- Thickness of Transdermal patch was measured by using Mitutoyo Digimatic Micrometer. Thickness of rectangular patch $(2 \times 2 \mathrm{cms})$ was determined at three different points and average thickness was calculated. Same was performed for other patches also. Thickness of each individual patch should not deviate significantly from each other.[11]

Weight variation:- Five films from each batch were weighed individually and average weight was calculated.[11$12]$

Percentage moisture uptake:- The films were weighed accurately and placed in the desiccators at room temperature for $24 \mathrm{hrs}$ and then exposed to $84 \% \mathrm{RH}$ using a saturated solution of potassium chloride. The films were weighed repeatedly until they showed a constant weight.

\section{$\%$ Moisture uptake $=\frac{\text { Final weight }- \text { Initial weight }}{\text { Initial weight }} \times 100$}

Folding Endurance:- Evaluation of folding endurance involves determining the folding capacity of the patches. Folding endurance is determined by repeatedly folding the patch at the same place until it breaks [13]. The number of times the patch could be folded at the same place without breaking is folding endurance value.

Drug Content Uniformity:- Amount of drug entrapped in a patch was determined by completely dissolving a patch of size $2 \times 2 \mathrm{~cm} 2$ in $100 \mathrm{ml}$ phosphate buffer solution (pH 7.4). Complete dissolution was achieved by placing the solution containing patch on shaker for about $24 \mathrm{hrs}$. Solution was then filtered and drug content was estimated spectrophotometrically at 208nm after suitable dilution.[13]

In vitro drug release:- The in-vitro release profile is an important tool that predicts in advance how a drug will behave in vivo. In-vitro studies were performed using a Franz diffusion cell with a receptor compartment capacity of $17 \mathrm{~mL}$. The receptor compartment was filled with phosphate buffer saline pH 7.4 and the cellophane membrane was mounted between the donor and receptor compartment of the diffusion cell. The prepared transdermal film was 
placed on the cellophane membrane. The whole assembly was kept on a magnetic stirrer and the solution was stirred continuously at $600 \mathrm{rpm}$ using a magnetic bead at $37^{\circ} \mathrm{C}$. The $2 \mathrm{~mL}$ of sample was withdrawn at different time interval and replaced with an equal volume of diffusion medium. Sample were analysed spectrophotometrically at $208 \mathrm{~nm}$ for the determination.[13] as given in Table 3.The Comparison of in-vitro drug release rate profile of different batches of transdermal patch containing Pregabalin was done as shown in Fig 4.

\section{F) Sciatic nerve injury constriction model:}

Anaesthetise the rat in an induction chamber using 99.9\% chloroform and monitor the anesthetised animal during the procedure. Shave the left hind leg of the rat and apply lubricating ophthalmic ointment to the eyes.Sterilize the shaved area with three alternate applications of 70\% isopropyl alcohol and iodine solution.Make an incision in the skin parallel, but 3-4 mm below the femur, and free the skin from the muscle surrounding the incision by cutting through the connective tissue. Using blunt scissors, cut through the connective tissue between the gluteus superficialis and the biceps femoris muscles. Using curved blunt-tipped forceps gently free approximately $10 \mathrm{~mm}$ of the sciatic nerve (proximal to the sciatic trifurcation) from the surrounding connective tissue as shown in Fig.7

\section{Result and discussion:-}

Result of evalaution parameters profile is shown in Table 3. Characterisation of patches is shown in Table 2. It was found to be 11.2 hours for most optimized formulation F-9. Less amount of neuropathic pain was seen in albino wistar test batch rats with pregabalin transdermal patch as shown in Fig.8-10. Skin irritation studies show no sign of erythma or any other skin irritation reaction, so it can be concluded that neither the drug nor any polymer or excipient was found to cause adverse effects on skin, hence, patch was found. Result of all evaluation parameters was found to be satisfactory within permissible limits as shown in Fig.5 and Fig.6
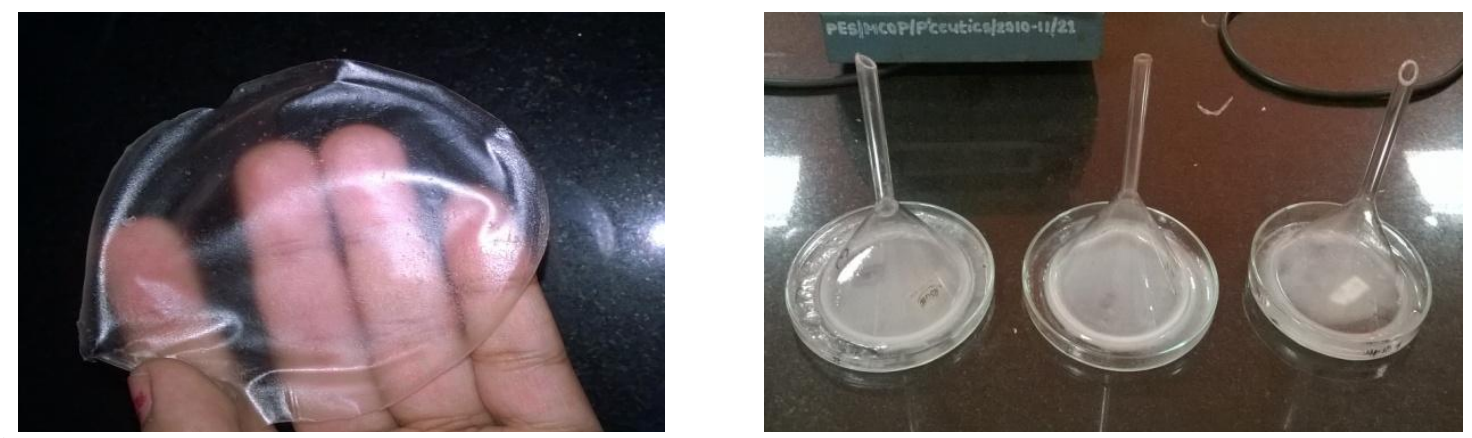

Fig. 1:- Development of Pregabalin Transdermal patches using solvent evaporation method (1A)Pregabalin Transdermal Patch (1B)Technology employed for preparation of patch.

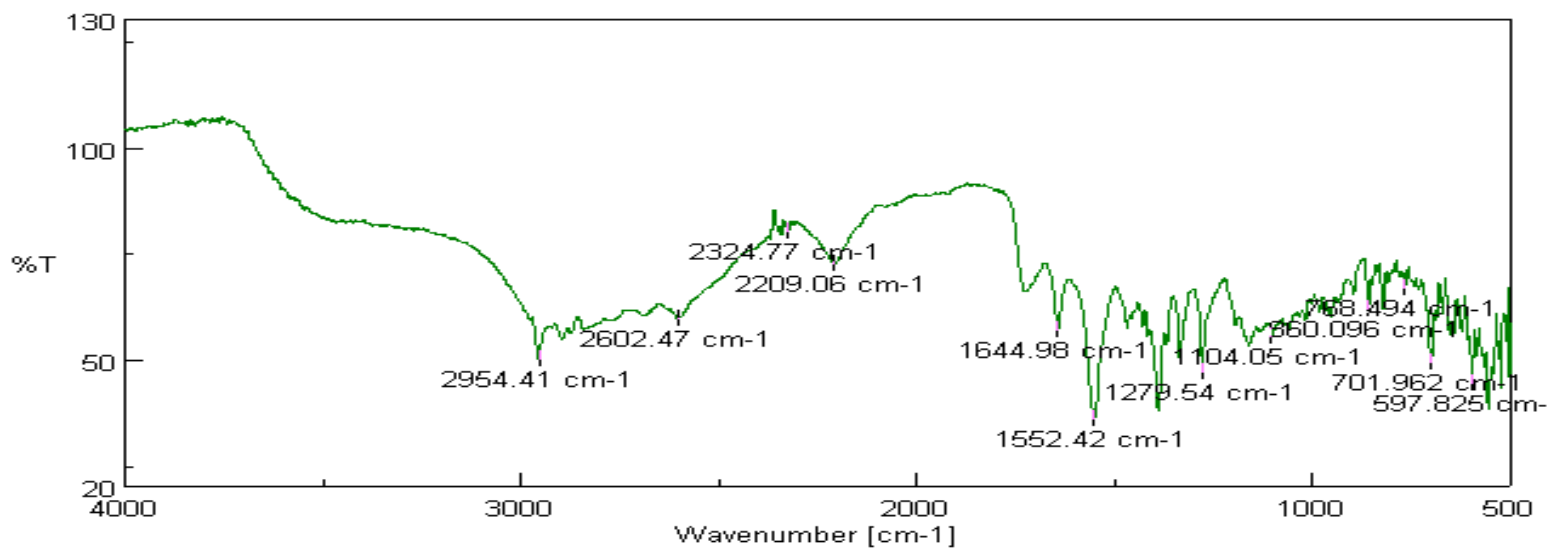

Fig.2:- FTIR study of drug (Pregabalin) with polymers HPMC E-15 and Eudragit RS-100. 

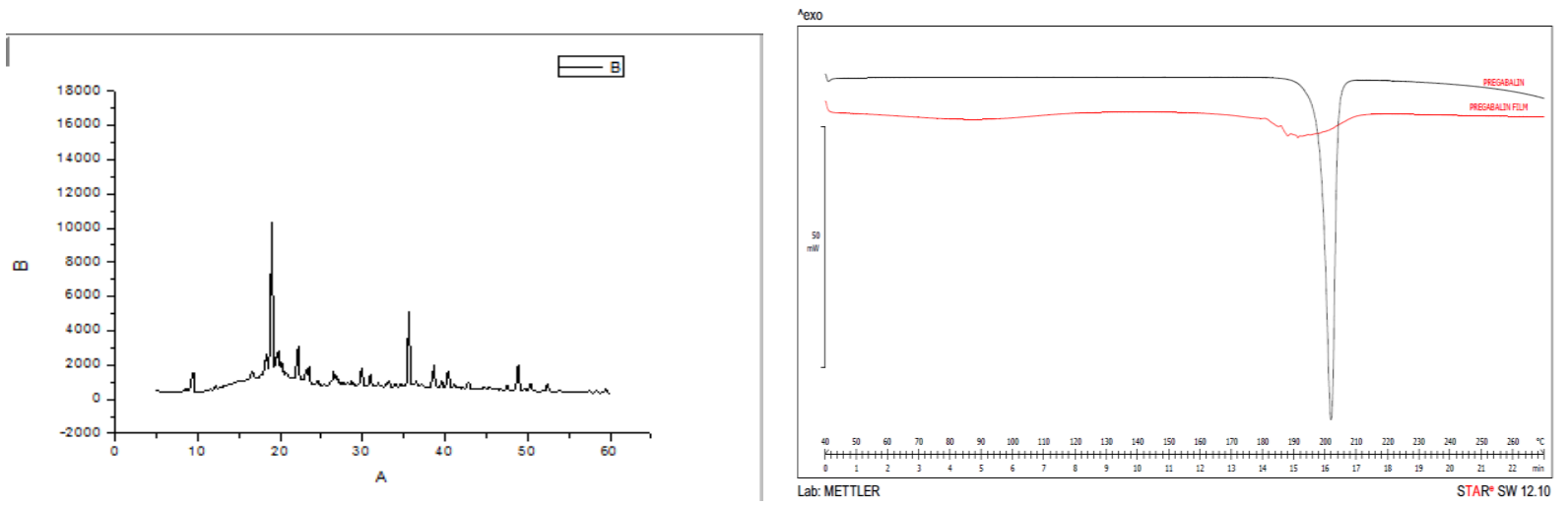

Fig. 3:- Drug and Physical mixture study (1A) X-ray diffraction study (1B) Differential scanning calorimetery

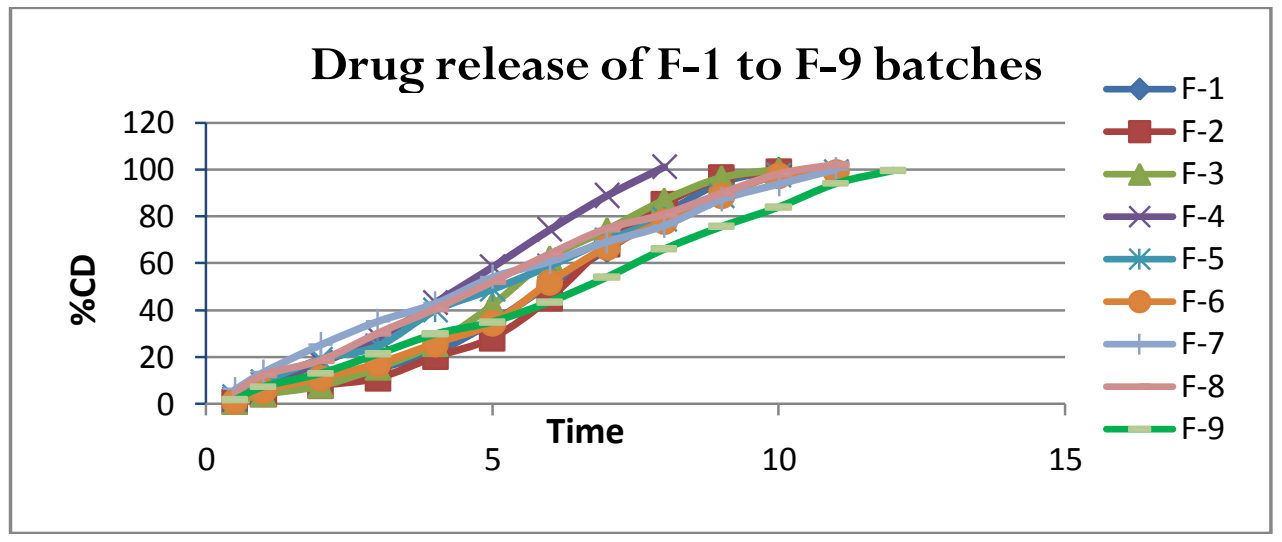

Fig.4:- Comparison of in-vitro drug release rate profile of different batches of transdermal patch containing Pregabalin.
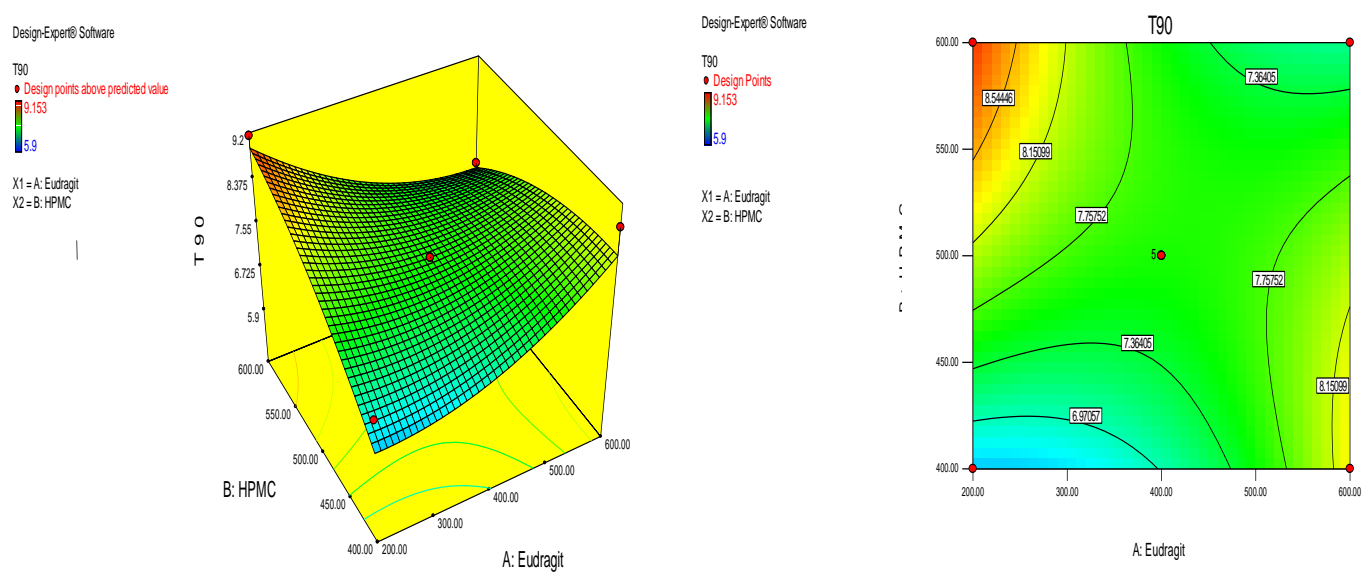

Fig. 5:- Effect of HPMC E-15 and Eudragit RS-100 on \% Drug Release at $\mathrm{T}_{90}$ (5A) Contour and (5B) Response surface plots. 

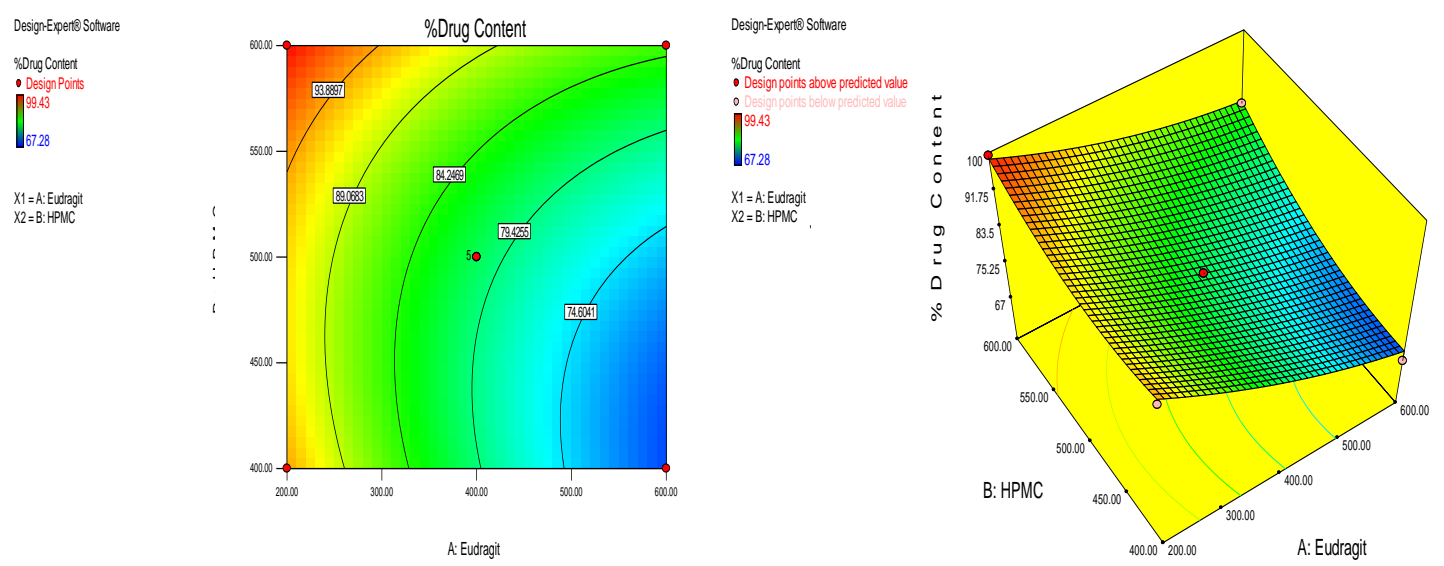

Fig.6:- Effect of HPMC E-15 and Eudragit RS-100 on Drug Content (6A) Contour and (6B) Response surface plots.

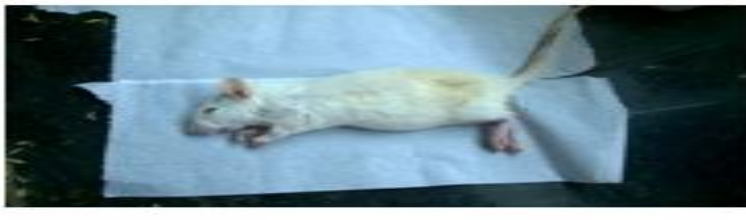

STEP I

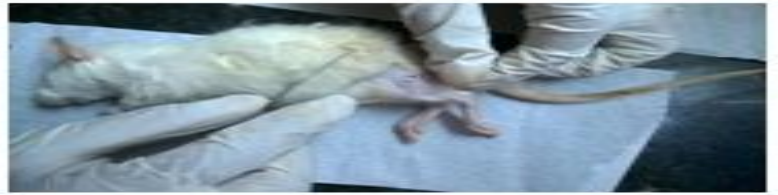

STEP

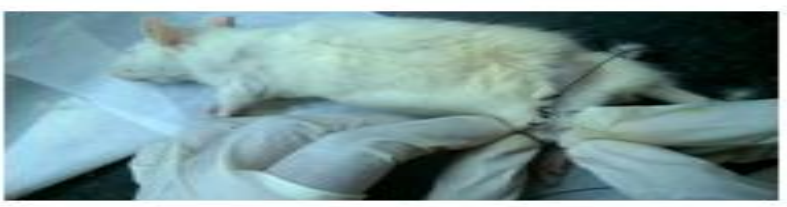

STEPS

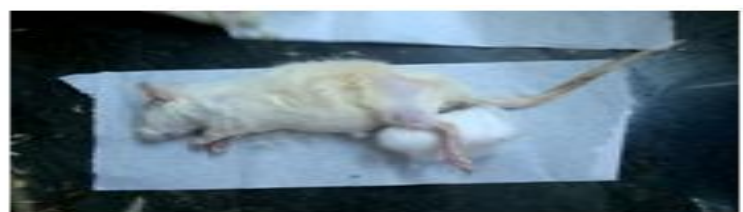

STEP2

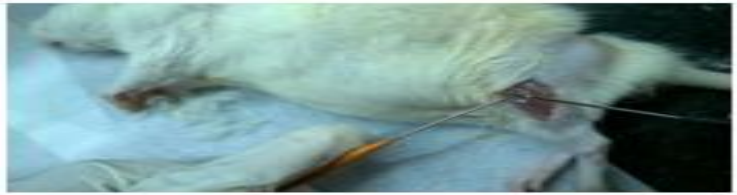

STEP 4

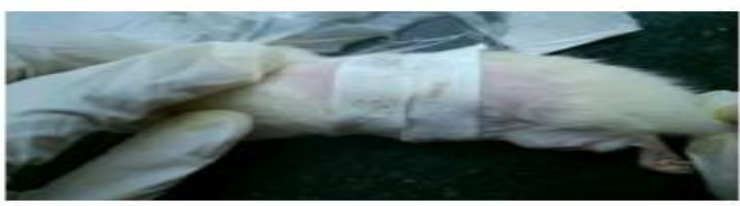

STEP 6

Fig.7 Step wise Procedure of sciatic nerve chronic constriction model.

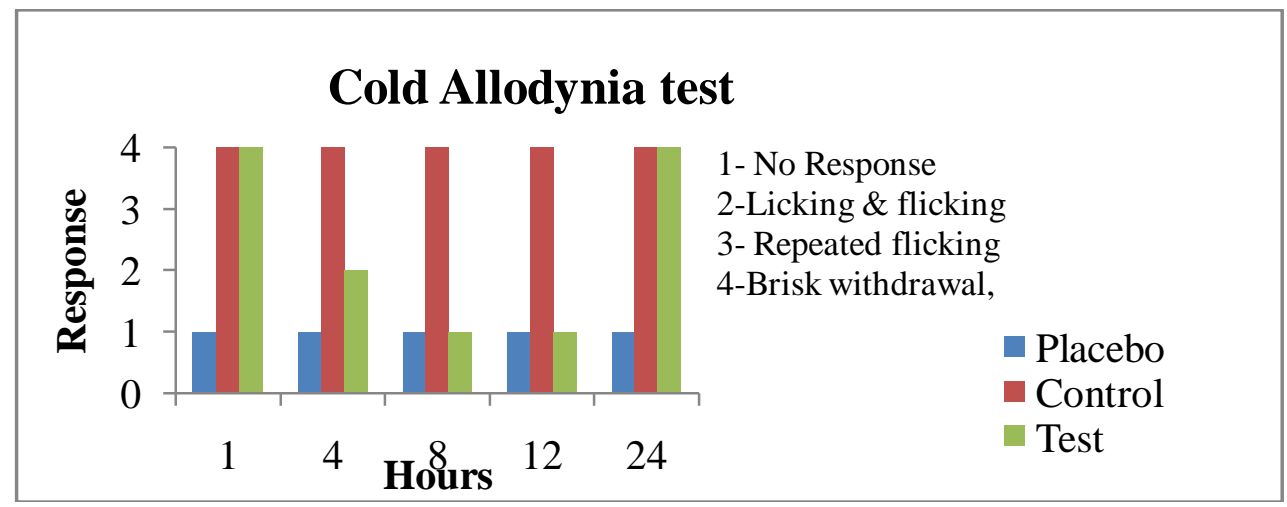

Fig.8 Cold allodynia test on wistar rats 


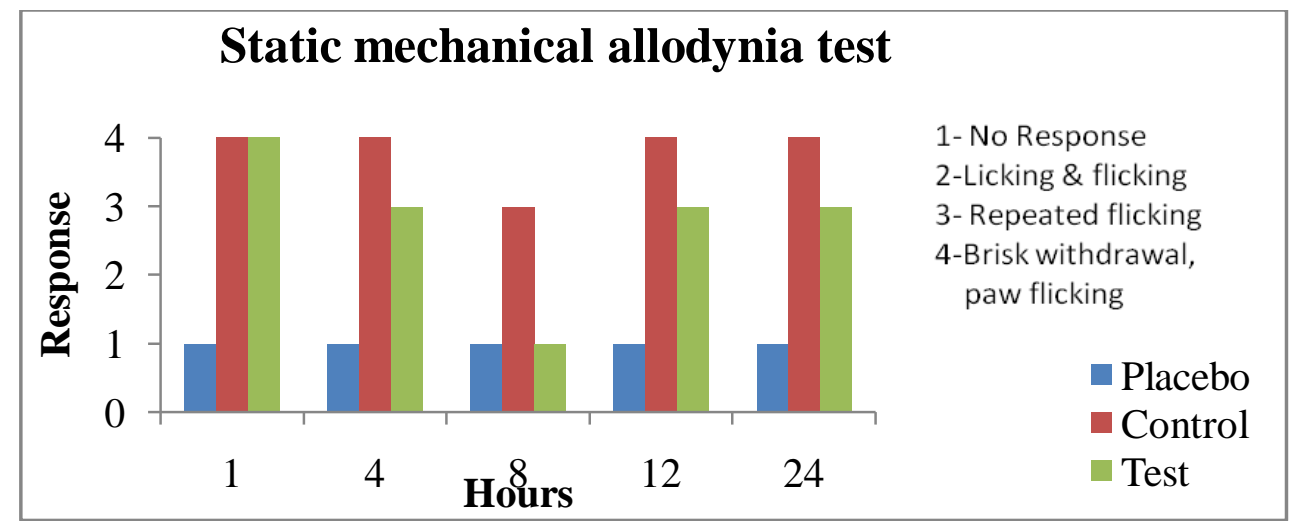

Fig.9 Static mechanical allodynia test on wistar rats

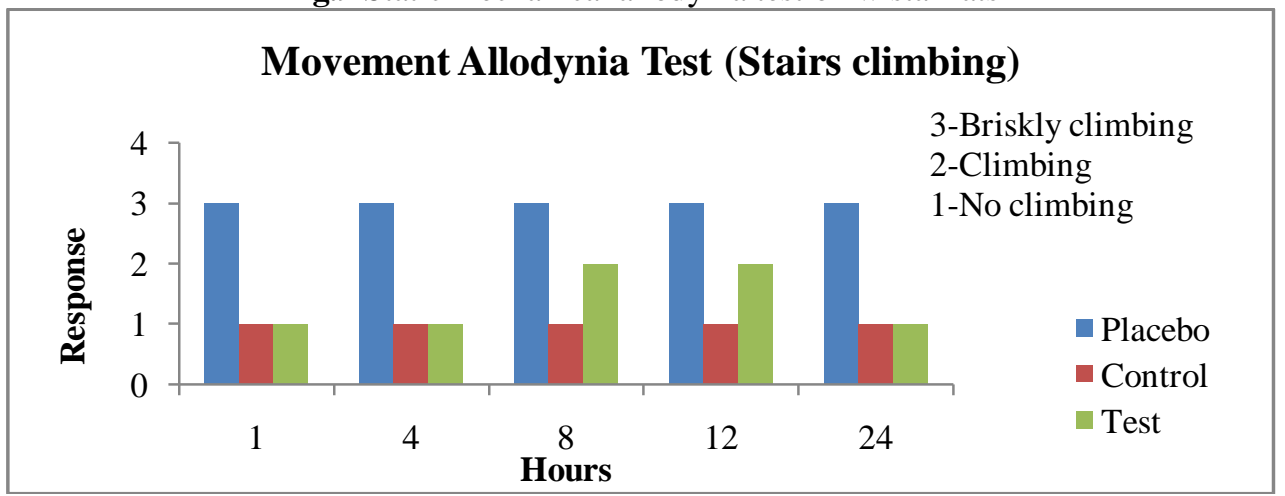

Fig.10 Movement allodynia (climbing) test on wistar rats

Table 1:- Composition of medicated patch of HPMC E-15 and Eudragit RS-100 in different ratios

\begin{tabular}{|l|l|l|l|l|l|}
\hline Formulation code & $\begin{array}{l}\text { Eudragit } \\
\text { RS100 }(\mathrm{mg})\end{array}$ & $\begin{array}{l}\text { HPMC E-15 } \\
(\mathrm{mg})\end{array}$ & $\begin{array}{l}\text { Solvent }(\mathrm{ml}) \\
\text { Water: Methanol }\end{array}$ & $\begin{array}{l}\text { n-butyl phathalate } \\
(\mathrm{ml})\end{array}$ & $\begin{array}{l}\text { DMSO } \\
(\mathrm{ml})\end{array}$ \\
\hline F-1 & 400 & 500 & $1: 9$ & 0.3 & 0.3 \\
\hline F-2 & 600 & 400 & $1: 9$ & 0.3 & 0.3 \\
\hline F-3 & 682.84 & 500 & $1: 9$ & 0.3 & 0.3 \\
\hline F-4 & 200 & 400 & $1: 9$ & 0.3 & 0.3 \\
\hline F-5 & 400 & 641.42 & $1: 9$ & 0.3 & 0.3 \\
\hline F-6 & 117.16 & 500 & $1: 9$ & 0.3 & 0.3 \\
\hline F-7 & 400 & 358.58 & $1: 9$ & 0.3 & 0.3 \\
\hline F-8 & 600 & 600 & $1: 9$ & 0.3 & 0.3 \\
\hline F-9 & 200 & & & 0.3 \\
\hline
\end{tabular}

Table 2:- Characterisation Pregabalin transdermal patches.

\begin{tabular}{|l|l|l|l|l|}
\hline Formulation code & Colour & Odour & Appearance & Texture \\
\hline F-1 & Colourless & Odourless & Uniform, Translucent & Smooth \\
\hline F-2 & Colourless & Odourless & Uniform, Translucent & Smooth \\
\hline F-3 & Colourless & Odourless & Uniform, Opaque & Smooth \\
\hline F-4 & Colourless & Odourless & Uniform, Translucent & Smooth \\
\hline F-5 & Colourless & Odourless & Uniform, Transparent & Smooth \\
\hline F-6 & Colourless & Odourless & Uniform, Transparent & Smooth \\
\hline F-7 & Colourless & Odourless & Uniform, Opaque & Smooth \\
\hline F-8 & Colourless & Odourless & Uniform, Transparent & Smooth \\
\hline
\end{tabular}


Table 3:- Evaluation parameters of Pregabalin transdermal patches

\begin{tabular}{|l|l|l|l|l|l|l|l|}
\hline Code & T90 $(\mathrm{h})$ & $\begin{array}{l}\text { Folding } \\
\text { endurance }\end{array}$ & $\begin{array}{l}\text { Weight } \\
\text { uniformity }(\mathrm{gm})\end{array}$ & $\begin{array}{l}\text { Thickness } \\
(\mathrm{mm})\end{array}$ & $\begin{array}{l}\text { \%Moisture } \\
\text { uptake }\end{array}$ & $\begin{array}{l}\text { \%Drug } \\
\text { content }\end{array}$ & Elongation \\
\hline F-1 & $9.9 \pm 0.3950$ & $107+0.577$ & $0.521+0.0049$ & $0.256+0.003$ & $2.54+0.05$ & $80.74+0.001$ & $21.23+0.001$ \\
\hline F-2 & $10.8 \pm 0.3$ & $94+2$ & $0.67+0.0060$ & $0.223+0.002$ & $2.3+0.005$ & $67.28+0.0005$ & $20.25+0.0055$ \\
\hline F-3 & $10.3 \pm 0.173$ & $97+1.527$ & $0.653+0.0162$ & $0.27+0.0057$ & $2.4+0.005$ & $73.41+0.0057$ & $22.36+0.0057$ \\
\hline F-4 & $9.2 \pm 0.3$ & $117+0.577$ & $0.524+0.0121$ & $0.23+0.0057$ & $3.6+0.011$ & $92.55+0.0055$ & $21.21+0.0057$ \\
\hline F-5 & $9.3 \pm 0.1527$ & $132+0.577$ & $0.555+0.0095$ & $0.23+0.0057$ & $3.2+0.005$ & $95.39+0.0020$ & $24.2+0.11269$ \\
\hline F-6 & $10.1 \pm 0.057$ & $114+0.577$ & $0.497+0.0060$ & $0.24+0.0037$ & $2.7+0.010$ & $98.23+0.023$ & $23.51+0.0057$ \\
\hline F-7 & $7.8 \pm 0.20$ & $123+0.577$ & $0.621+0.0005$ & $0.23+0.0057$ & $2.4+0.015$ & $83.88+0.0057$ & $23.01+0.0635$ \\
\hline F-8 & $9.2 \pm 0.0057$ & $119+0.577$ & $0.52+0.00057$ & $0.236+0.001$ & $5.8+0.011$ & $84.48+0.005$ & $25.06+0.01$ \\
\hline F-9 & $11.2 \pm 0.080$ & $145+0.577$ & $0.548+0.0005$ & $0.22+0.0005$ & $2.2+0.005$ & $99.43+0.0052$ & $25.61+0.0063$ \\
\hline
\end{tabular}

\section{Conclusion:-}

From the above study it can be concluded that Pregabalin can be administered as sustain drug delivery system via matrix type transdermal drug delivery system, which provides controlled release which ultimately reduces the frequency of administration of drug in patients suffering from neuropathic pain, epilepsy and fibromyalgia. Hence this non-invasive, non-irritating, compatible patch with ease of application and removal may find increase patient compliance. The animal studies on albino wistar rats showed less neuropathic pain in test batch but present work required to be supported by further studies involving histological studies and human models.

\section{Acknowedgement:-}

I am thankful to Modern College of Pharmacy, Nigdi, Pune for providing all the facilities for completion of this research work. I would like to acknowledge the support of Dr. P. D. Chaudhari and Mr. Samarth Kaluskar (University Of Toronto) for their help throughout the study.

\section{References:-}

1. Ministry of Health and Family Welfare, Indian Pharmacopoeia, Government of India, 2010.

2. Remington, "The Science and Practice of Pharmacy", B.I. Publications, 21st edition, 2006, Volume 1: 871-876.

3. Chien Y.W, "Novel drug delivery system", 2nd edition, 2006, volume-50, C: 139-143.

4. Gujral RS, African Journal of Pharmacy and Pharmacology, 2009, Volume-3(6), 327-334.

5. Salem H, E-Journal of Chemistry, 2009, Volume-6(2), 332-340.

6. Taylor CP, CNS Drug Rev, 2004, Volume-10, 159- 164.

7. Fink K, et al, J Pharmacol, 2000, Volume-130, 900 - 906.

8. Ameringen MV, et al, Europ Psych, 2008, Volume-23(2), S221-S222.

9. Banker G.S., Rhodes C.T., "Modern pharmaceutics", Marcel dekker Inc., fourth edition, 2002: 667.

10. Naik A. et al, "Transdermal delivery-overcoming skin's barrier function", Pharmaceutical Science and Technology Today, 2000, drug Volume-3, Issue-9,318-326.

11. Damecha D.L., "Drug vehicle based approaches on penetration enhancement", International Journal of Pharmacy and Pharmaceutical Sciences, July 2009, Volume-1, Issue 1, 24-46.

12. Benson A.E.H, "Transdermal Drug Delivery: Penetration Enhancement Technique", Current Drug Delivery, 2005, Volume-2, 23-33.

13. Ghosal K, Rajabalaya R, Kishore AM,Chowdhury B, Nanda A. Evaluation of physicochemical properties and in-vitro release profile of Glipizide- matrix patch. Brazzilian J Pharm Sci, 2010, Volume-46(2), 213-218. 